\title{
Las audiencias públicas: ¿escenificaciones de la discusión pública?
}

\author{
María Virginia Romanutti \\ Corina Echavarria \\ Recibido: 24 de agosto de 2018 \\ Aceptado: 12 de noviembre de 2018
}

\section{Resumen}

Las audiencias públicas son espacios participativos instituidos desde el Estado, generalmente, con el objetivo de construir consensos en torno de las acciones públicas. Sin embargo, su funcionamiento y eficacia para incidir en las decisiones de política pública es objeto de debate, cuestionándose tanto las condiciones de su implementación como las posibilidades del desarrollo de la deliberación en este espacio.

El objetivo de este trabajo es dar cuenta del diseño y funcionamiento de las audiencias en el ámbito de la municipalidad de la ciudad de Córdoba (Argentina). Para ello, en un diálogo permanente entre las experiencias de observación participante -vinculada a la participación de las autoras en la Red Ciudadana Nuestra Córdoba- y la construcción teórica derivada del modelo deliberativo, nos interesa analizar el funcionamiento de las audiencias públicas entendiéndolas como escenificaciones de la discusión pública.

\section{Palabras clave}

Audiencias públicas, escenificaciones y espacio público.

\begin{abstract}
Public hearings are participatory spaces instituted from the State, generally, with the aim of building consensus around public actions. However, its operation and effectiveness in influencing public policy decisions is the subject of debate, questioning both the conditions of its implementation and the possibilities for the development of deliberation in this space.

* Docente e investigadora de la Facultad de Ciencia Política y Relaciones Internacionales de la Universidad Católica de Córdoba, y de la Facultad de Ciencias Sociales de la Universidad Nacional de Córdoba, Argentina.

** Docente e investigadora CIECS-CONICET, IFFAP, Facultad de Ciencias Sociales, Universidad Nacional de Córdoba
\end{abstract}


Las audiencias públicas: ¿escenificaciones de la discusión pública?

María Virginia Romanutti y Corina Echavarria

DOI: http://dx.doi.org/10.22201/fcpys.20071949e.2019.31.65991

The objective of this work is to give an account of the design and operation of the public hearings in the area of the municipality of the city of Córdoba (Argentina). For this, in a permanent dialogue between the experiences of participant observation -linked to the participation of the authors in the citizen network "Nuestra Córdoba"- and the theoretical construction derived from the deliberative model, we are interested in analyzing the functioning of public hearings, understanding them as staging of public discussion.

\section{Key words}

Public hearings, staging and public space.

\section{Introducción}

Las audiencias públicas son espacios participativos instituidos desde el Estado, generalmente, con el objetivo de construir consensos en torno de las acciones públicas. Sin embargo, su funcionamiento y eficacia para incidir en las decisiones de política pública es objeto de debate, cuestionándose tanto las condiciones de su implementación como las posibilidades del desarrollo de la deliberación en este espacio.

En la ciudad de Córdoba (Argentina), desde los debates de la Carta Orgánica (1995) se reconoce como idea fuerza el desarrollo de un municipio de plena participación ciudadana y se incorporan diversas formas de democracia semidirecta hasta institucionalizar la formulación participativa del presupuesto municipal (2008). Entre las instituciones vigentes, distinguimos las Audiencias Públicas que reconocen como antecedente, en el mundo anglosajón, las reuniones públicas vinculadas al cercamiento de las tierras comunitarias y la General Inclosure Act (1845), donde las decisiones del parlamento fueron alternadas con reuniones públicas (cf. Kemp, 1987); mientras que en el hispano, remiten a los cabildos abiertos de la tradición colonial y a las asambleas económicas provenientes del derecho español del siglo XIX, en los cuales "sólo participaban la parte más sana (españoles y sus descendientes)" (Brügge y Mooney, 1998: 389). En ambos casos, se trata de instituciones de carácter excepcional (para situaciones de emergencia o definición de nuevas pautas para la regulación de la potestad de imposición económica del Estado). Sin embargo, las últimas jugaron un rol decisivo en los procesos emancipatorios asumiendo el ejercicio del poder soberano (decisión acerca del orden normativo y selección de autoridades).

Actualmente, en la ciudad de Córdoba (Argentina) son una "instancia de participación ciudadana", habilitada por la autoridad municipal, para que "la comunidad interesada en informarse o en participar en la toma de decisiones administrativas y/o legislativas se exprese de manera directa", sin carácter resolutivo (Ord.11709/2009, art 2 y 4). 
Las audiencias públicas: ¿escenificaciones de la discusión pública?

María Virginia Romanutti y Corina Echavarria

DOI: http://dx.doi.org/10.22201/fcpys.20071949e.2019.31.65991

El objetivo de este trabajo es dar cuenta del diseño y funcionamiento de las audiencias en el ámbito de la municipalidad de la ciudad de Córdoba (Argentina), durante el período 20122016. Para ello, en un diálogo permanente entre las experiencias de observación participante -vinculadas a la participación de las autoras en la Red Ciudadana Nuestra Córdoba ${ }^{1}$ - y la construcción teórica derivada del modelo deliberativo, nos interesa analizar cómo funcionan las audiencias públicas, poniendo el foco de análisis en la escenificación de la discusión pública.

En este sentido, imaginar el mundo como un teatro es un recurso al que las personas recurren en su vida cotidiana, pero también a modo de hipótesis de trabajo consideramos que, como ha sido observado en la literatura y parafraseando a Sennett, es un recurso analítico para introducir la ilusión y el engaño en la vida política. En este ejercicio, dice el autor a partir de Balzac, podemos identificar 'roles' o las "máscaras diversas y necesarias que las personas utilizan en diferentes situaciones" o la "conducta en situación específica" (2011: 53-54).

En la recolección de datos ${ }^{2}$ se han utilizado las siguientes técnicas: observación participante del momento deliberativo de las audiencias públicas; análisis de documentos de los registros administrativos y de las versiones taquigráficas de los debates de las audiencias públicas acontecidas en el período 2012-2016; entrevistas a informantes claves y seguimiento de medios de comunicación (metadatos: Audiencia, Plan de Metas, Presupuesto, Córdoba). ${ }^{3}$

En tal sentido, cabe destacar los límites que se derivan de la forma en la que se construye la información pública, en el ámbito del Concejo Deliberante de la ciudad, y el acceso a la misma. A partir del trabajo realizado es posible afirmar que no hay uniformidad en la construcción de la información (por ejemplo, en los registros administrativos se dejó de consignar la diferencia entre oyentes y exponentes entre los participantes en las audiencias públicas, o al menos esa información ya no se procesa, tampoco se discrimina para todas las sesiones quienes lo hacen de manera individual o en representación de alguna organización). Todo esto demanda

\footnotetext{
${ }^{1}$ La red ciudadana Nuestra Córdoba es un espacio de acción colectiva, constituido por más de 60 organizaciones de la ciudad de Córdoba: organizaciones sociales, universidades, colegios profesionales, empresas, centros de investigación, centros vecinales, ciudadanos que trabaja sobre problemáticas de la ciudad generando información, espacios de debate y movilización ciudadana e incidencia en políticas públicas. En el marco de este último objetivo promovió la sanción de la ordenanza Plan de Metas de Gobierno.

${ }^{2}$ Agradecemos el trabajo de recolección y sistematización de datos realizado por Marina Rosales, estudiante de la Facultad de Ciencia Política y RRIII, Universidad Católica de Córdoba, que realizó su práctica profesional en el Grupo Temático Democracia Participativa de la Red Ciudadana Nuestra Córdoba.

${ }^{3}$ El trabajo se ha desarrollado en el marco de los siguientes proyectos de los que han participado las autoras: "Democracia Deliberativa en Córdoba: análisis de los alcances y limitaciones de algunas experiencias participativas, contribuciones para su factibilidad (UCC, 2010-2011)", "Participación ciudadana y rendición de cuentas en la ciudad de Córdoba" (MinCyT/UCC, 20122013) y “Meta-requisitos, instituciones y prácticas de la Democracia Local” (UCC, 2014-2017).
} 
Las audiencias públicas: ¿escenificaciones de la discusión pública?

María Virginia Romanutti y Corina Echavarria

DOI: http://dx.doi.org/10.22201/fcpys.20071949e.2019.31.65991

un trabajo de interpretación, de participantes y analistas, a partir de los dichos de los actores participantes, en el caso de este trabajo, recuperados de los diarios de sesiones y registros de campo.

En un primer apartado del trabajo presentamos las audiencias públicas como institución participativa en el marco de los modelos de gestión actuales, especialmente, destacando las particularidades que su diseño asume en la experiencia local cordobesa. En un segundo momento, recurrimos a uno de los referentes en el análisis dramatúrgico: Ervin Goffman; quien, en su trabajo "La presentación de la persona en la vida cotidiana" (1968), procura ofrecer un marco de referencia para estudiar la vida social dentro de los límites de una organización. Entonces, abordamos los elementos propuestos por el autor, para avanzar en la descripción detallada y comprensión de las interacciones que tienen lugar en las audiencias públicas.

\section{La participación ciudadana en la gestión de gobierno a través de audiencias públicas}

Al analizar los diversos mecanismos institucionales participativos que se desarrollan a nivel local, podemos ubicar a las audiencias públicas entre las instituciones que implican la participación de los actores no estatales en el momento de toma de decisiones respecto de la formulación de políticas públicas. Esto es, establecimiento de prioridades y asignación de los recursos, incluyendo la formulación de programas (cf. Rofman, 2007). Un caso especial, a nivel local, sería el de las audiencias vinculadas a la implementación de los Planes de Metas de Gobierno ${ }^{4}$ donde, como afirmáramos en otro trabajo, la participación vía audiencia se da no sólo en la formulación -ex-ante- sino a lo largo del proceso de implementación (durante), hasta la evaluación de resultados -ex-post- (cf. Echavarría \& Díaz, 2013).

Algunos autores enfatizan el papel de las audiencias públicas como mecanismos de participación que se focalizan en el diagnóstico de problemas y avanzan en la construcción de la agenda local, distinguiéndolos así de aquellos que tienen un carácter más decisional, dado que en general su implementación no tiene carácter vinculante, y de los que suponen la participación ciudadana en el proceso de gestión (Font et al, 2012). En este último aspecto, nuevamente,

\footnotetext{
${ }^{4}$ El Plan de Metas de Gobierno es una ordenanza que establece la obligatoriedad por parte del Poder Ejecutivo Municipal de presentar su plan de gobierno expresado en metas medibles, de modo tal que la ciudadanía pueda hacer seguimiento de la gestión gubernamental (ordenanza 11.942). Hemos realizado un análisis detallado del funcionamiento de las audiencias públicas en el proceso del Plan de Metas de Gobierno en Romanutti y Echavarria (2015).
} 
Las audiencias públicas: ¿escenificaciones de la discusión pública?

María Virginia Romanutti y Corina Echavarria

DOI: http://dx.doi.org/10.22201/fcpys.20071949e.2019.31.65991

el caso de las audiencias vinculadas a la implementación del Plan de Metas de Gobierno es diferente a los demás en cuanto posibilita un ajuste de la agenda establecida por el gobierno y el seguimiento del proceso de implementación de las metas establecidas por éste, a través de audiencias públicas periódicas (anuales) en las que se discuten los informes de avance del plan en cuestión.

La oportunidad para la publificación de cuestiones y su potencial para la construcción de agenda de gobierno tienen como base la igualdad formal que sustenta la convocatoria y composición de estos espacios. Esto es, las audiencias son espacios donde potencialmente cualquier ciudadano, puede presentar sus demandas, observaciones, críticas, sobre los temas objeto de debate y ser oído no sólo por sus pares sino también por sus representantes o las autoridades pertinentes.

En el marco de un análisis más general acerca de los mecanismos de control social, Cunill Graw advierte las fortalezas de espacios como las audiencias públicas para la formación de una "arena pública de mediación entre la esfera estatal y la esfera social", y "tornar más abierto el ejercicio del poder, facilitando la formación democrática de opinión pública" (Cunill Graw, 2002: 208 y 209). Sin embargo, al examinar lo que ocurre en la práctica a nivel latinoamericano, concluye que no estarían dadas las condiciones para que estas instituciones sean verdaderos "foros ciudadanos de deliberación en torno a los procesos de formación de las decisiones y políticas públicas" (Cunill Graw, 2002: 209). Más allá que en la práctica se verifican numerosas dificultades para el desarrollo de deliberación en estos espacios; su implementación creciente en la actualidad es defendida con base en una serie de características (Gaba, 2000: 6), tales como:

- Involucran a los destinatarios de la decisión en el proceso de informar sobre las alternativas, opiniones, intereses y puntos de vista relacionados con el tema. En este sentido, el beneficio de la realización de la audiencia alcanza no sólo a los funcionarios que deben tomar luego la decisión objeto de debate, sino a los ciudadanos participantes de la audiencia, en tanto les permite obtener información sobre los asuntos de su interés o que los afectan (suponiendo que la convocatoria va acompañada de la información sobre el tema en cuestión) y participar y/o incidir en el proceso de formación no sólo de la opinión sino también de la voluntad pública sobre la temática en cuestión.

- Mantienen la transparencia y publicidad de los temas que se debaten. El desarrollo de las audiencias públicas se plantea como una garantía de que la temática ha sido sometida al debate público; lo que implicaría un mayor grado de legitimidad de las decisiones públicas posteriores sobre el tema; en la medida que en la audiencia todas las voces han tenido la 
Las audiencias públicas: ¿escenificaciones de la discusión pública?

María Virginia Romanutti y Corina Echavarria

DOI: http://dx.doi.org/10.22201/fcpys.20071949e.2019.31.65991

oportunidad de ser escuchadas.

Según lo establecido por la normativa de creación de las audiencias públicas en la ciudad de Córdoba, las audiencias son una "instancia de participación ciudadana", habilitada por la autoridad municipal, para que "la comunidad interesada en informarse o en participar en la toma de decisiones administrativas y/o legislativas se exprese de manera directa”, sin carácter resolutivo: "la autoridad municipal responsable de la decisión, puede expresar en los fundamentos del acto administrativo o legislativo que se sancione, de qué manera ha tomado en cuenta las opiniones vertidas en aquélla y -en su caso- las razones por las cuales las desestima" (Ord.11709/2009, arts 2 y 4).

El momento de uso público de la palabra se concreta en una sesión del Concejo Deliberante de la ciudad, abierta a la participación de los vecinos. Sin embargo, cabe destacar que según lo previsto y como sucede en la mayoría de los casos, no existe obligación por parte de la autoridad de dar cuenta o considerar los debates y/o opiniones vertidas por los ciudadanos durante la audiencia, ni argumentar acerca de las razones por las cuales fueron desestimadas. Las audiencias públicas asumen funciones informativas y/o consultivas para con los ciudadanos y sus resoluciones pueden no ser vinculantes para las decisiones del sistema político administrativo.

En el análisis de la implementación de este instituto en la ciudad de Córdoba, identificamos una serie de dificultades y condicionantes para el logro efectivo de estos propósitos, que parten tanto del diseño de la institución como de las formas en las que efectivamente se 'escenifica' el diálogo público.

\section{La escenificación de la discusión pública}

\footnotetext{
"El escenario teatral presenta hechos ficticios; la vida muestra, presumiblemente, hechos reales, que a veces no están bien ensayados”.

Goffman (1997:I I)
}

Cuando intentamos aprehender las interacciones que tienen lugar en las audiencias públicas en términos dramatúrgicos, podemos distinguir -siguiendo a Goffman (1997)- los siguientes elementos: el escenario (setting); la fachada (front); la actuación (performance); los papeles (rutinas); trasfondo escénico y distancia social. 
Las audiencias públicas: ¿escenificaciones de la discusión pública?

María Virginia Romanutti y Corina Echavarria

DOI: http://dx.doi.org/10.22201/fcpys.20071949e.2019.31.65991

El escenario, "incluye el mobiliario, el decorado, los equipos y otros elementos propios del trasfondo escénico" ante, dentro o sobre el que se desarrolla el "flujo de acción". Goffman destaca la importancia de los escenarios para el desarrollo de las interacciones, particularmente, cuando se trata de la administración, de la medicina (hospitales), entre otros. En términos geográficos, dice el autor, el escenario tiende a permanecer 'fijo' y opera como condición de posibilidad de las interacciones o performance de los diferentes actores: "Ios que usan un medio determinado como parte de su actuación no pueden comenzar a actuar hasta haber llegado al lugar conveniente, y deben terminar su actuación cuando lo abandonan.” (Goffman, 1997: 34)

En el escenario es posible distinguir la fachada: "parte del escenario que funciona regularmente de un modo general y prefijado a fin de definir la situación con respecto a aquellos que observan dicha actuación" (Ritzer, 1993:246). A su vez, en la fachada Goffman (1997) distingue entre el 'medio' y la 'fachada personal'. El primero, hace referencia al escenario físico que rodea a los actores para su actuación, mientras que la segunda, consiste en las partes escénicas de la dotación expresiva que la audiencia identifica con los actores y que espera que lleven al escenario (vestimenta, accesorios, modales, expresiones). Para el caso particular de análisis de este texto, podemos prestar especial atención a la "capacidad estatutaria" del actuante o locutor considerado legítimo (por la posesión de un título y/o atributos institucionales); parafraseando a Bourdieu, la posesión de una competencia legítima que tienen los actuantes para hacer uso de la palabra oficial, es decir, formal, en ocasiones especiales (Bourdieu, 2001: 43).

En el marco de los escenarios, los participantes realizan su actuación (performance), la cual a su vez contribuye/influencia al desarrollo de otras (coparticipantes, audiencia, observadores) en un período determinado, por la copresencia en un espacio tiempo. La actuación refiere, entonces, a "toda actividad de un individuo que tiene lugar durante un período señalado por su presencia continua ante un conjunto particular de observadores y posee cierta influencia sobre ellos" (Goffman, 1997:33).

Las pautas de acción pre-establecidas que pueden ser actuadas o presentadas por los participantes son denominadas, por el autor, papeles o rutinas. Desde esta perspectiva, es posible afirmar que los individuos en su interacción con los demás representan diferentes 'papeles' de acuerdo a la situación en que se encuentran, de manera de actuar como se considera socialmente correcto. Es decir, interpretan un personaje, sin embargo, a diferencia del espacio teatral, en la 'vida real' los posibles papeles se condensarían en dos, subsumiendo a los participantes y sus papeles en el público, citamos en extenso:

[...] en el escenario el actor se presenta, bajo la máscara de un personaje, ante los personajes proyectados por otros actores; el público constituye el tercer partícipe de la interacción, un partícipe fundamental, que sin embargo no estaría allí si la representación escénica fue- 
Las audiencias públicas: ¿escenificaciones de la discusión pública?

María Virginia Romanutti y Corina Echavarria

DOI: http://dx.doi.org/10.22201/fcpys.20071949e.2019.31.65991

se real. En la vida real, estos tres participantes se condensan en dos; el papel que desempeña un individuo se ajusta a los papeles representados por los otros individuos presentes, y sin embargo estos también constituyen el público (Goffman, 1997: 11).

Dos elementos, particularmente considerados por el autor, cargan de sentido tanto al escenario como a las actuaciones que en él se desarrollan: el trasfondo escénico y la distancia social. En el primero, hacen aparición los elementos (hechos o tipos de acciones) suprimidos/ocultos de la actuación, porque son "capaces de desvirtuar la impresión suscitada". En tal sentido, "puede definirse como un lugar, relativo a una actuación determinada, en el cual la impresión fomentada por la actuación es contradicha a sabiendas como algo natural" (Goffman, 1997: 122-123). Finalmente, la referida distancia alude a "las restricciones puestas sobre el contacto", un camino, dice el autor, "en el cual se puede originar y mantener un temor reverente en el público [...] en el cual el público puede ser mantenido en un estado de mistificación en relación con el actuante." (Goffman, 1997: 78).

\section{Mirando las escenas}

Como dijimos, las Audiencias Públicas se desarrollan, generalmente, en el recinto del Concejo Deliberante de la ciudad. En principio, integrarse al ámbito físico de deliberación oficial suele ser bien considerado por los ciudadanos participantes que identifican en esto una valoración del espacio destinado a la participación en el proceso de toma de decisiones (cf. Echavarría, 2000). Sin embargo, en estas ocasiones la disposición habitual de los actores en el espacio se rediseña, asumiendo la forma de un cuadrado que puede describirse como lo hacemos a continuación.

La mesa de las autoridades preside la sesión (llustración 1). Se encuentra en una posición que resulta central para el que accede al recinto y elevada con una tarima respecto del resto de los participantes. Generalmente, este espacio lo ocupa el Presidente del Concejo Deliberante, órgano que convoca a la audiencia. En el caso particular de las audiencias del Plan de Metas de Gobierno, el Intendente ocupa dicho espacio y habla desde allí cuando presenta el Plan o rinde cuentas, mientras a un lado el equipo de gestión del municipio acompaña la participación del intendente. Del lado opuesto, el titular del poder (Ilustración 2); el público que se ha convocado para participar de la Audiencia ocupa el lugar que habitualmente le es asignado en las discusiones públicas delegadas del legislativo local: espectador en la platea. 
Ilustración 1: Las autoridades que presiden la sesión están en el estrado (fondo, arriba); los concejales en sus bancas (izquierda); y una vecina realizando su intervención (derecha).

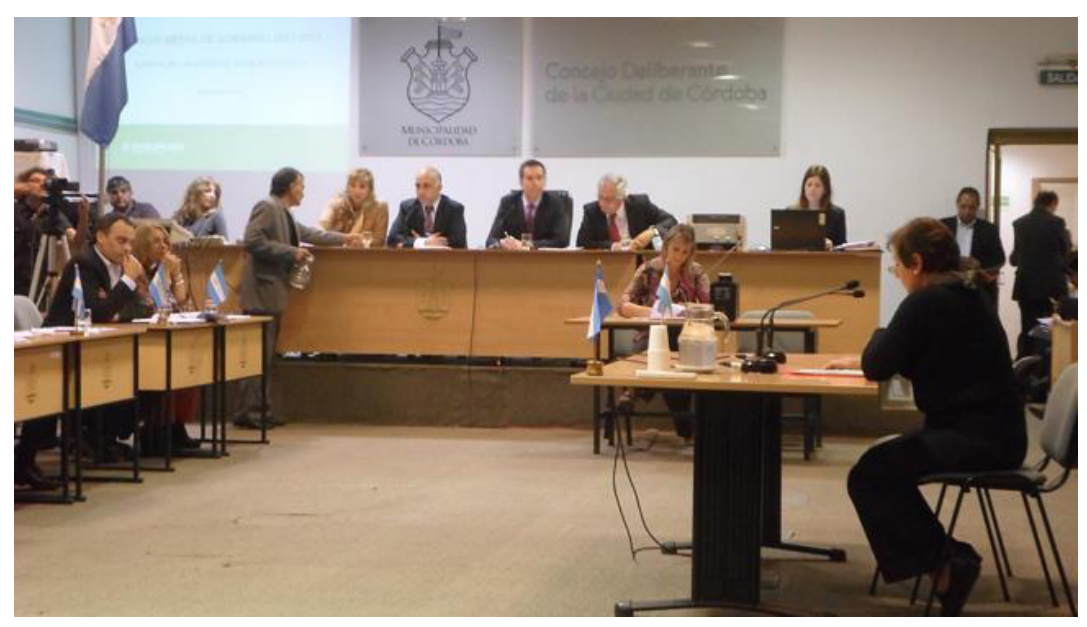

Fuente: Audiencia del Consejo Deliberante de la Ciudad de Córdoba.

Ilustración 2: El público asistente/oyente ubicado al fondo del salón.

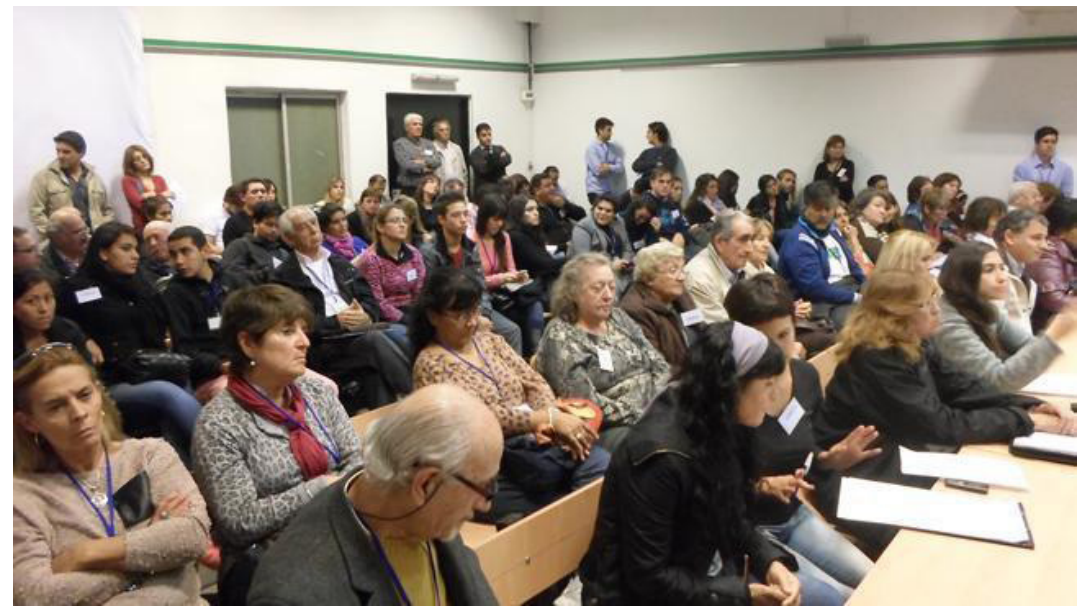

Fuente: Audiencia del Consejo Deliberante de la Ciudad de Córdoba.

En cruz, el eje de la deliberación (llustración 1 y 3), los que pueden argumentar en torno de las informaciones, proyectos y/o avances presentados por la autoridad: los concejales, de un 
lado, y los vecinos, del otro. Los primeros, los representantes del pueblo, ya no miran al frente, lugar que ocupa la presidencia, su mirada se dirige a un "nuevo espacio" -de tipo ocasional/ coyuntural- en el que hacen uso de la palabra los vecinos y organizaciones que participan de la sesión. Los concejales, eventualmente, lo harán desde sus bancas. Este eje, cuando es observado desde la posición del público espectador pierde visibilidad frente a la autoridad que se encuentra sobre-elevada. (Ver ilustración 1, 2 y 3)

llustración 3: Debajo del estrado, los funcionarios municipa-

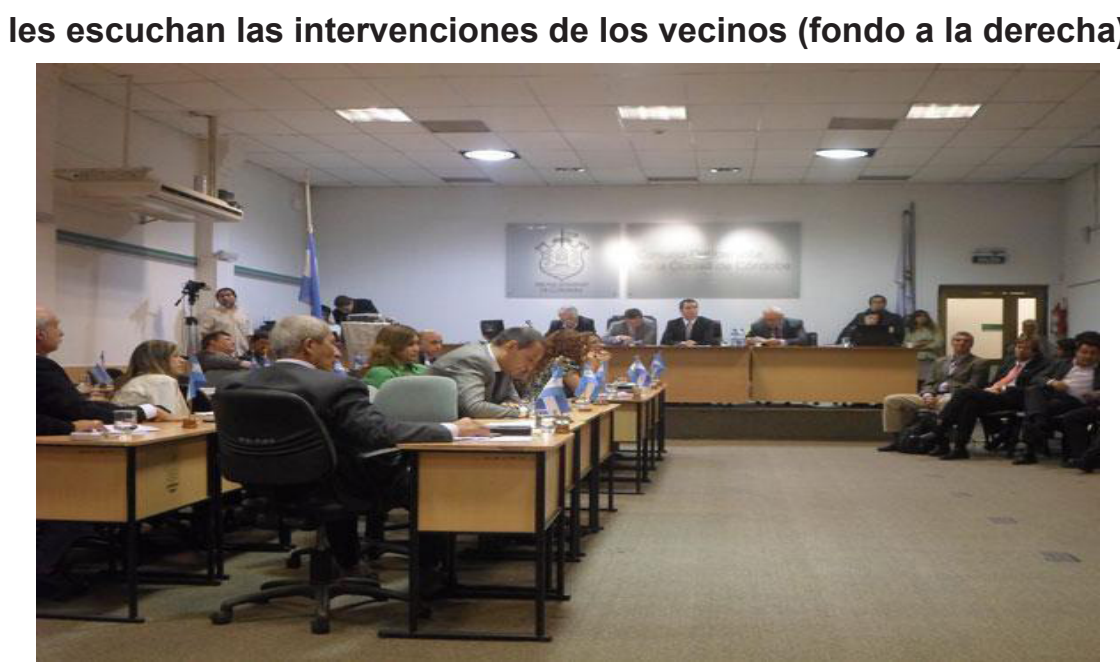

Fuente: Audiencia del Consejo Deliberante de la Ciudad de Córdoba.

Así dispuesto, el medio organiza el flujo de las interacciones y el juego de oposiciones entre los actores/participantes y la audiencia/público, en el diálogo entre representantes y representados (concejales/ciudadanos) y condicionando la horizontalidad democrática del espacio en el eje autoridades/ciudadanos. También se integran aquí un juego de 'apariencias' y 'modales' que describen rutinas diferentes en la misma fachada.

En principio, podemos identificar a los actores participantes teniendo en cuenta su capacidad estatutaria. Esto es, considerando el orden normativo vigente, los actores reconocidos por la Carta Orgánica Municipal (Poder Ejecutivo, Concejales y Centros Vecinales), distinguiéndolos de aquellos para quienes la participación se amplía en el marco de las leyes que regulan las Audiencias Públicas ('vecinos' de manera individual u organizada).

Entonces, en el Estado Municipal, los papeles que desempeñan los participantes reconocidos por la norma que organiza el ejercicio del poder municipal son: los que pertenecen al poder legislativo (el viceintendente que preside el órgano deliberativo y sus integrantes, los conce- 
Las audiencias públicas: ¿escenificaciones de la discusión pública?

María Virginia Romanutti y Corina Echavarria

DOI: http://dx.doi.org/10.22201/fcpys.20071949e.2019.31.65991

jales) y los miembros del departamento ejecutivo (el intendente y su equipo), en caso de ser pertinente. Cabe destacar, en este punto, que la audiencia de Plan de Metas de Gobierno es la única que exige, como dijéramos más arriba, la presencia del Poder Ejecutivo Municipal como 'miembro informante' en la deliberación, que en el caso de las otras audiencias es ejercido por alguno de los concejales de la bancada mayoritaria.

\section{Las rutinas del Estado Municipal en las audiencias}

La rutina que define a las audiencias públicas, el uso de la palabra, se caracteriza por la brevedad en el uso del tiempo, respondiendo la cantidad de ciudadanos potencialmente afectados por los asuntos en discusión que participan de los procesos deliberativos. Es en función de esto que, en principio, se produce una selección de temas; la presentación que realiza el miembro informante define la agenda de la Audiencia. En los casos observados, las autoridades legislativas y/o ejecutivas deliberadamente definen aquellos asuntos y/o acciones sobre los que ponen el énfasis de la argumentación, así como también cuáles soslayar para el tratamiento del tema en cuestión. En el caso del Plan de Metas, los secretarios y funcionarios municipales que acompañan al mandatario local se integran a la rutina del ejecutivo; estos no sólo avalan el mensaje sino que además su presencia y modales orientan significativamente las subsecuentes intervenciones de los vecinos participantes, las que se dirigen hacia los responsables administrativos de las acciones de gobierno, sacando el foco del responsable del gobierno y a los interlocutores previstos: los concejales.

Son los concejales, como representantes del pueblo, los que han de tomar la decisión en cuestión y para esto habrán de recabar durante la audiencia la información necesaria, proveniente tanto de las intervenciones de los vecinos como de las presentaciones de los informantes del tema en cuestión. Para esto, pueden también interpelar a los participantes e inclusive abrir el debate. En el Plan de Metas de Gobierno, además, se les asigna el rol de contralor del cumplimiento de las obligaciones derivadas de la ordenanza (formal-procedimental). ${ }^{5}$ Sin embargo, su desempeño pareciera darse en el natural vaivén

\footnotetext{
${ }^{5}$ Esto es, la presentación del Plan y de los informes anuales en base a los contenidos mínimos establecidos en la norma (art.2, ordenanza 11.942/11). Asimismo, están facultados para realizar propuestas o recomendaciones, solicitar informes ampliatorios y aclaratorios y sugerir medidas, para mejorar el proceso de evaluación de cumplimiento del Plan (art.7, Ord. 11.942/11). Es decir, para este caso, la función del Concejo Deliberante se ciñe al control procedimental, a lo que se le suma la difusión del Plan y los informes de avance (art. 5).
} 
Las audiencias públicas: ¿escenificaciones de la discusión pública?

María Virginia Romanutti y Corina Echavarria

DOI: http://dx.doi.org/10.22201/fcpys.20071949e.2019.31.65991

entre el cinismo ${ }^{6}$ y la sinceridad, parafraseando a Goffman, en la medida en que -según lo observado-limitan su participación a la función de escucha de las diferentes voces que allí se hacen presentes, para luego refrendar las propuestas sometidas a debate sin mayores alteraciones.

En este sentido, los concejales no solo conservan los elementos del medio, que refuerzan sus apariencias -status- y los distinguen del resto de los participantes en la Audiencia, sino que además se remiten a la rutina habilitada por la norma, casi como mediadores/árbitros entre el gobierno y los ciudadanos reorientando los flujos de interacción previstos, donde los titulares (público y expositores) del poder quedan visual y funcionalmente por debajo de las autoridades municipales.

\section{Las rutinas de los "vecinos"}

En las audiencias públicas, si consideramos la necesidad de autorización que experimentan los gobiernos en los asuntos que allí se someten a discusión pública, el 'otro' sería: el Pueblo, el conjunto de los ciudadanos y sus organizaciones. Sin embargo, aquí nuevamente la disquisición de Bourdieu adquiere sentido, y podemos distinguir: los centros vecinales (y otras instituciones reconocidas normativamente como las Juntas de Participación Vecinal) de otros tipos de organizaciones y vecinos que participan. Estas diferencias que provendrían de la legitimidad de las palabras de unos y otros, también se observan en los modales y valores privilegiados en las respectivas alocuciones.

En los registros taquigráficos de las audiencias es posible reconocer tres tipos de estructuras de la argumentación entre los participantes, según estén centradas: en el reconocimientos de las acciones públicas del gobierno municipal, en la demandas de acciones públicas o intervenciones puntuales del mismo gobierno u observaciones y/o críticas al proyecto objeto de debate en la audiencia. A partir de este ejercicio analítico, observamos que los centros vecinales, reconocidos en la Carta Orgánica Municipal como organizaciones representantes de los vecinos, dividen el uso de la palabra, principalmente, entre el reconocimiento de las acciones públicas de la gestión de gobierno y la presentación de demandas por la falta de políticas públicas sobre diversos temas (asfalto, alumbrado, desagües) que los afectan en sus barrios,

${ }^{6}$ Dice Goffman: “...el actuante puede querer guiar la convicción de su público solo como un medio para otros fines, sin un interés fundamental en la concepción que de él o de la situación tiene este. Cuando el individuo no deposita confianza en sus actos ni le interesan mayormente las creencias de su público, podemos llamarlo cínico..." (1997: 29) 
Las audiencias públicas: ¿escenificaciones de la discusión pública?

María Virginia Romanutti y Corina Echavarria

DOI: http://dx.doi.org/10.22201/fcpys.20071949e.2019.31.65991

independientemente de las cuestiones que son objeto de debate. Algunos ejemplos de estas intervenciones son:

"Como vecino de esta ciudad quiero destacar la labor realizada por el doctor Ramón Mestre, nuestro intendente, y todo su grupo de trabajo, quienes otorgan la oportunidad de mejorar y participar en las actividades políticas dejando de lado las diferencias e intereses, poniendo énfasis a un proyecto de avance para nuestra ciudad...." (Centro Vecinal Villa Páez, audiencia plan de metas 2012)

"En general, quiero reconocer todas las obras de la ciudad. Hay muchas que no se ven, pero que hacen a la mejor calidad de los vecinos. Y por todo lo que se ha hecho, en especial en mi barrio. Ojalá que podamos tener de nuevo esta gestión por cuatro años más para que tengamos la ciudad que nos merecemos...." (Centro Vecinal Villa Unión, audiencia plan de metas 2015)

"Mi presencia se debe al reclamo de ciertas gestiones que hemos realizado, que en cierta manera se han cumplimentado -estoy agradecido por eso- aunque queda pendiente el tema de la luz, porque tenemos tres luminarias caídas y varias calles a oscuras..." (Centro Vecinal Barrio Ituzaingó, Audiencia plan de metas 2012)

"Días pasados, en otra Audiencia, llamé un poco a la reflexión porque tenemos necesidades de todo tipo. Si se quiere, hemos sido dejados de lado. Hicimos muchas peticiones al Ejecutivo, de diversa índole. Les voy a nombrar algunas, si me alcanza el tiempo. Por ejemplo, un basural a cielo abierto, un lugar contaminante para ustedes y nosotros que vivimos en el barrio; un desagüe a cielo abierto, que las inmundicias más altas pasan por él. Puedo seguir nombrando: falta de asfalto en muchos lugares que se inundan, pasan días y días y los vecinos no pueden salir de sus casas."(Centro Vecinal barrio Marqués Anexo, audiencia plan de metas 2014)

No obstante, la gran mayoría de estas intervenciones se realizan a partir de la experiencia particular, por ejemplo: "para mí y para muchos vecinos..." (Centro Vecinal Barrio Villa Libertador, audiencia Plan de Metas 2016); "tengo la necesidad de resaltar lo realizado..." (Centro Vecinal Barrio Villa Páez, Audiencia plan de metas 2012); "nos ha beneficiado porque tenemos 5 líneas de colectivos que nos llevan a casi toda la ciudad..." (Centro Vecinal Barrio Alta Córdoba, audiencia plan de metas 2014); "deseo que estos dos pliegos sean superadores..." (Junta de Participación Vecinal del Centro de Participación Comunal Colón, Audiencia Pública de Higiene Urbana y Transporte 2012). Lo real, lo verosímil, lo legítimo, se encuentra vinculado a lo que rutinariamente es 'sentido' por los vecinos y limita la creación de una 'geografía pública'. Como señala Sennett (2011), realizando un "paralelo social adulto" no se estaría dando el proceso de distinción entre el yo y el no-yo, lo que condiciona el debate integral sobre la ciudad.

Son las intervenciones individuales o registradas a título individual y las de las organizaciones 
Las audiencias públicas: ¿escenificaciones de la discusión pública?

María Virginia Romanutti y Corina Echavarria

DOI: http://dx.doi.org/10.22201/fcpys.20071949e.2019.31.65991

sociales, las que se balancean entre las demandas y las observaciones al proyecto que es objeto de discusión. Hablamos de intervenciones 'registradas a título personal' porque a través de las observaciones realizadas se advierten acciones de los vecinos o ciudadanos orientadas a tensionar los rituales tal y como están previstos, esto es, los diferentes participantes también despliegan diversas estrategias para poder transmitir su mensaje. Por ejemplo, dividir las intervenciones entre distintos participantes, de modo tal de hacer un uso eficiente del tiempo y lograr desarrollar de manera completa las ideas, reflexiones y/o demandas de sus colectivos de referencia.

Cabe aclarar que cuando se trata de participación organizacional entra en vigor el artículo 25 de la Ordenanza 11709, según la cual sólo pueden designar 1 (uno) miembro que las represente para el uso de la palabra. Esto es, más allá de la diversidad de temáticas sobre las que trabaje la organización o los límites de tiempo que impone la dinámica de la sesión, las organizaciones deberán ajustarse a una única intervención de hasta 5 (cinco) minutos. Esto estaría derivando en otras estrategias de presentación/identificación de los participantes a la hora de su registro, por ejemplo inscribirse como "vecino particular" aunque las observaciones que presenta en la audiencia sean fruto del debate colectivo dentro de una organización. Todo lo cual diluye la presencia/visibilidad de los actores colectivos que se involucran en el debate y cotidianamente se articulan en torno de los asuntos sometidos a audiencia pública. Esto se evidencia claramente en las audiencias por el Plan de Metas de Gobierno, donde en 2014 y 2016 se observa un aumento significativo del peso relativo de la participación individual respecto de la participación organizada entre los que hacen uso de la palabra, que partiendo del $20 \%$ en 2012 se eleva a $40 \%$ y $30 \%$ respectivamente.

En lo que respecta a la diferenciación de papeles, un rol importante lo cumple el público 'oyente' (¿audiencia?) que acompaña el desarrollo de la sesión, entre quienes se encuentran tanto los miembros de las organizaciones descritas como también los ciudadanos simpatizantes del gobierno municipal. Estos últimos, usualmente intervienen al reforzar el mensaje brindado por el intendente municipal, al informar el Plan de Metas de Gobierno, a través de aplausos y diversas expresiones de aprobación para el mismo y/o de desaprobación para quienes presentan observaciones críticas al tema en discusión.

Así, se conforma el repertorio de la actuación en el escenario antes descrito donde cada actor tiene un lugar asignado; asegurando la eficacia de todo el acto. La distancia existente entre las autoridades que presiden la sesión, ubicadas en lo alto y el resto de los participantes, refuerza la distancia social existente entre ambos, contribuyendo, en términos de Goffman (1997: 80), a "mistificar" la actuación. Es decir, a infundir respeto en la audiencia y mantener la credibilidad 
Las audiencias públicas: ¿escenificaciones de la discusión pública?

María Virginia Romanutti y Corina Echavarria

DOI: http://dx.doi.org/10.22201/fcpys.20071949e.2019.31.65991

de la actuación mediante la limitación del contacto físico y la ubicación diferencial en el espacio de los vecinos y las autoridades. Como sostienen los autores de Parliament en una nota para el sitio web World Economic Forum, "La arquitectura también moldea la cultura política, las diferencias entre los actores se organizan en el espacio..." (Ordóñez Chillaron, 2016). En el que caso bajo análisis se trata de un modelo de parlamento en el que los ciudadanos y sus representantes están enfrentados; lo cual de acuerdo a los analistas parece democrático por la igualdad de enfrentamiento entre unos y otros. No obstante, su origen es autoritario: "El monarca se colocaba en la posición central, simbolizando la concentración del poder absoluto" (Ordóñez Chillaron, 2016), tal y como acontece en el caso bajo análisis donde, como ya señalamos, quien preside la sesión se ubica en lugar central y sobre-elevado del resto.

Finalmente, otras estrategias contribuyen a la eficacia de la actuación: las que se desarrollan en el 'trasfondo escénico', tras bambalinas, donde todo se prepara, incluyendo las acciones informales que quedan ocultas al público. Así, por ejemplo, la preparación de los discursos que serán dichos en la Audiencia con su respectiva construcción de agenda (selección de temas, logros a destacar por parte de las autoridades y problemas a invisibilizar o minimizar); así como la definición del orden de los expositores (facultad que posee el vice intendente en tanto presidente de la audiencia), todo hace posible la manipulación del "clima" o "tono" que prevalecerá en la reunión. En el decorrer de las Audiencias hemos observado que, para la intervención de los ciudadanos se ubican al comienzo a aquellos expositores que reconocen las acciones de gobierno en la temática en cuestión, dejando para el final a aquellos que se presume que harán hincapié en las observaciones a los proyectos presentados y en las demandas de acciones públicas. Esta práctica dilatoria de los discursos críticos acaba limitando el alcance de los mismos en la medida en que avanzada la hora de la reunión, los ciudadanos registrados para exponer comienzan a desertar antes de hacer uso de la palabra, además de los medios de comunicación que, generalmente, concentran las coberturas en el discurso del informante y los primeros expositores.

\section{Conclusiones. Democracia condescendiente}

Al utilizar el recurso analítico de imaginar las audiencias públicas como teatro y describir el escenario, las fachadas, rutinas, trasfondos escénicos y la propia distancia social que se construye en cada una de las Audiencias Públicas, es posible afirmar en principio que: en el Concejo Deliberante de la ciudad de Córdoba (Argentina), con la particular disposición del mobiliario que se utiliza en las audiencias se ordenan espacialmente a los actores intervinientes y con- 
Las audiencias públicas: ¿escenificaciones de la discusión pública?

María Virginia Romanutti y Corina Echavarria

DOI: http://dx.doi.org/10.22201/fcpys.20071949e.2019.31.65991

dicionan los flujos de comunicación posibles, reforzando performances y rituales propios de la democracia representativa. Podríamos pensar siguiendo a Goffman en la falta de ensayo que evidencian los espacios donde se teatraliza la democracia local, particularmente, en el marco de la crisis o agotamiento de la representación como ficción legitimante de las democracias representativas. En este sentido, la implementación de estas y otras formas de la participación ciudadana parecieran formar parte de una estrategia "condescendiente" de los gobiernos, de los representantes elegidos por el voto popular para la legitimación de decisiones colectivamente vinculantes.

\section{¿Condescendiente?}

Recurrimos entonces a Bourdieu, cuando al analizar los intercambios lingüísticos, habla de la "negación simbólica" de las jerarquías, de la "relación de fuerzas objetiva [entre las lenguas] que en la práctica se enfrentan..." (Bourdieu, 2001: 42). Semejante estrategia, para el autor, es posible en todos aquellos casos en que la diferencia objetiva entre las personas en presencia (es decir, entre sus propiedades sociales) es lo bastante conocida y reconocida por todos (y en particular por quienes están presentes, como agentes y espectadores, en la interacción) para que la negación simbólica de la jerarquía (la que consiste, por ejemplo en mostrarse "simple") permita acumular los beneficios vinculados a ella y lo que procura la negación completamente simbólica de esta jerarquía. Empezando por el refuerzo que implica el reconocimiento concebido a la manera de utilizar la relación jerárquica.

Esto es, las audiencias públicas constituyen un espacio que se pretende integrado en condiciones de igualdad, donde los ciudadanos recuperarían el ejercicio del poder delegado; donde, en consecuencia, se niegan las diferencias entre los participantes en el proceso de toma de decisiones efectivas. Es decir, se sostiene la paridad entre representantes y representados y de allí la apertura de este espacio para escuchar los posicionamientos de los vecinos sobre los asuntos que los afectan.

Asimismo, la aparente suspensión de las jerarquías y/o prerrogativas de unos y otros se completa si tenemos en cuenta, como señalamos anteriormente, que los argumentos esgrimidos por los participantes e inclusive aquellos que pudieran ser construidos en dicho espacio de intercambio intersubjetivo no son vinculantes para el proceso de toma de decisiones que habilitan/legitiman, así como tampoco existe obligatoriedad por parte de las autoridades de dar una respuesta a las opiniones vertidas en la audiencia. Por tanto, se trata de un espacio donde representantes y representados actúan "como si" estuvieran en pie de igualdad y, fundamentalmente, "como si" la opinión de los vecinos fuera relevante para definir la voluntad colectiva que orienta la intervención del Estado. 
La democracia que excepcionalmente se pone en acto en la implementación de estas instituciones, dista del carácter instituyente que históricamente habría asumido, para reforzar -en la estructuración de las interacciones- la autoridad delegada, el desacoplamiento de los representantes. Cada una de las Audiencias, podría ser tenida, siguiendo la propuesta de Goffman, como una situación fija/estática equilibrada en los roles que en ella se desarrollan: escenas sin argumento, sin experiencia, a decir de Sennett (2011).

Sin embargo, el estudio longitudinal realizado de las Audiencias Públicas en la ciudad de Córdoba, nos ha permitido dar cuenta de algunos cambios que evidencian el aprendizaje en la participación de los ciudadanos, que ponen en tensión el engaño, fundamentalmente, resistiendo a las relaciones de fuerza sostenidas tras bambalinas en las audiencias. Esto es, a pesar de todas las falencias descriptas, la participación ciudadana en las audiencias públicas se sostiene, en especial en aquellas que se repiten anualmente como son las de presupuesto y plan de metas de gobierno. A su vez, la experiencia desarrollada por los ciudadanos hace que desplieguen diversas estrategias para hacer escuchar su voz: distribuir una única presentación entre varios para poder decir todo lo que desean sin infringir la norma que restringe la alocución a los cinco minutos, visibilizar sus intervenciones en los medios de comunicación en el caso de aquellos que participan en representación de organizaciones, entre otras estrategias. Esto último plantea la importancia que cobra la amplificación de la escena más allá del recinto legislativo, lo cual abre una serie de interrogantes para seguir analizando la cuestión: ¿En qué medida la eficacia de las actuaciones desarrolladas en las audiencias públicas depende de sus repercusiones en la agenda mediática? ¿Cuáles son las alocuciones ciudadanas que logran pasar a la escena mediática y por qué? 


\section{Fuentes de información}

Bourdieu, P. (2001), ¿Qué significa hablar? Economía de los intercambios lingüísticos, Madrid, España: Ediciones Akal.

Brugge, Juan y Mooney, Alfredo (1998), Derecho Municipal Argentino: aspectos teóricos y prácticos, Córdoba: Francisco Ferreyra Editor.

Concejo Deliberante (2011), "Ordenanza N 11.942: Plan de Metas de Gobierno, instrumento de planificación e información ciudadana”, Córdoba, Argentina, disponible en < http:// www.cordoba.gov.ar/Digestoweb/Page/Documento.aspx ?Nro=23792 > (fecha de consulta: 2 de junio de 2018).

Concejo Deliberante (2012), "Audiencia Pública. Plan de Metas del gobierno de la Ciudad de Córdoba, Versión Taquigráfica, 28/06/2012”, Córdoba, Argentina.

Concejo Deliberante (2013), “Decreto L0288, 16/04/2013”, Córdoba, Argentina.

Concejo Deliberante (2013), “Audiencia Pública. Plan de Metas, Versión Taquigráfica, 25/04/2013”, Córdoba, Argentina.

Cunill Grau, Nuria (2002), "Nudos críticos de la accountability social. Extrayendo lecciones de su institucionalización en América Latina", en Peruzzotti E. y Smulovitz, C., Controlando la política. Ciudadanos y Medios en las nuevas democracias Latinoamericanas, Buenos Aires: Temas Grupo Editorial.

Echavarría, C. (2000), "Democratización del espacio público municipal mediante la implementación de instituciones de gestión participativa. Los casos de la Municipalidad de Córdoba - Argentina y de la Prefectura de Porto Alegre - Brasil”, Tesis de Maestría, Córdoba: Instituto de Investigación y Formación en Administración Pública, Universidad Nacional de Córdoba.

Echavarría, C. \& Díaz, A. C. (2013), “La oportunidad y los sujetos de la evaluación en políticas públicas: Una aproximación a dos casos de estudio en Córdoba Ciudad, el Plan de Metas de Gobierno y los CICs", Paraná: XI Congreso Nacional de Ciencia Política, organizado por la Sociedad Argentina de Análisis Político y la Universidad Nacional de Entre Ríos. 
Las audiencias públicas: ¿escenificaciones de la discusión pública?

María Virginia Romanutti y Corina Echavarria

DOI: http://dx.doi.org/10.22201/fcpys.20071949e.2019.31.65991

Font (2012), "Mecanismos de participación ciudadana en la toma de decisiones locales. Una visión panorámica", en Serie Documentos de Debate CLAD, año 7, número 50, disponible en: http://www.clad.org/siare_isis/fulltext /0038104.html (fecha de consulta: 3 de junio de 2018).

Gaba, Marta L. (2000), “La participación ciudadana en la gestión de gobierno a través de audiencias públicas", XIV Concurso de Ensayos y Monografías del CLAD sobre Reforma del Estado y Modernización de la Administración Pública: Administración Pública y Ciudadanía, Caracas: Centro Latinoamericano de Administración para el Desarrollo.

Goffman, E. (1997), La presentación de la persona en la vida cotidiana, Buenos Aires: Amorrortu editores.

Kemp, Ray (1987), "Planning, Public Hearings, and the Politics of Discourse", en Forester, John, Critical Theory and Public Life, USA: Mit Press.

Ordóñez Chillaron, Esteban (2016), “¿Cómo influye la arquitectura del Parlamento en la política?", World Economic Forum, disponible en <https://es.weforum.org/agenda/2016/11/ como-influye-la-arquitectura-en-la-politica?utm_content=buffer1bc05\&utm_medium=social\&utm_source=facebook.com\&utm_campaign=buffer> (fecha de consulta: 1 de junio de 2018).

Red Ciudadana Nuestra Córdoba (2013), “Informe del Plan de Metas 2012-2013”, Córdoba: Mimeo.

Red Ciudadana Nuestra Córdoba (2013) “¿Qué es el Plan de Metas?” Córdoba: Red Ciudadana Nuestra Córdoba, disponible en < http://nuestracordoba.org.ar/ plan-metas-gob > (fecha de consulta: 27 de enero de 2015).

Ritzer, G. (1996), “Teoría Sociológica Contemporánea”, Madrid: McGraw-Hill.

Rofman, Adriana (2007), Participación de la sociedad civil en políticas públicas: una tipología de mecanismos institucionales participativos, VI Conferencia Regional de ISTR para América Latina y el Caribe. Salvador de Bahía, Brasil.

Romanutti, Virginia (2012), "Plan de Metas en Córdoba: Una experiencia de incidencia colectiva”, Córdoba: Red Ciudadana Nuestra Córdoba. Disponible en: <http://www.nuestracordoba.org.ar/documentos/Sistematizacion_Plan_Metas_Cordoba.pdf > (fecha de consulta: junio de 2013). 
Romanutti, Virginia y Echavarria, Corina (2012), "Instrumentos de rendición de cuentas y participación ciudadana: aprendizajes en América Latina”, Córdoba: Red Ciudadana Nuestra Córdoba. Disponible en: <http://www.nuestracordoba.org.ar/documentos/Plan_Metas_ Aprendizajes_en_America_Latina.pdf > (fecha de consulta: junio de 2013).

Romanutti, Virginia y Echavarria, Corina (2014), "La factibilidad de la deliberación sobre los recursos públicos: diseños institucionales y prácticas de la ciudadanía en la ciudad de Córdoba", en Revista Más Poder Local, número 20, disponible en: <http://www.maspoderlocal.es/files/articulos/183-F53b2bb571831404222295-articulo-1.pdf > (fecha de consulta: 1 junio de 2018).

Romanutti, Virginia y Echavarria, Corina (2015), "El carácter deliberativo de las audiencias públicas: oportunidades y problemas para la participación ciudadana", presentado en II Encontro Internacional Participação, Democracia e Políticas Públicas, Brasil: Universidad Estatal de Campinas.

Sennett, Richard (2011), “El declive del hombre público”, Barcelona: Editorial Anagrama. 
Las audiencias públicas: ¿escenificaciones de la discusión pública?

María Virginia Romanutti y Corina Echavarria

DOI: http://dx.doi.org/10.22201/fcpys.20071949e.2019.31.65991

\section{$\sum_{i=4}$}

\section{E N C R U C I J A D A \\ REVISTA ELECTRÓNICA DEL \\ CENTRO DE ESTUDIOS EN \\ ADMINISTRACIÓN PÚBLICA}

$31^{\circ}$ NÚMERO ENERO-ABRIL 2019

\section{Revista Electrónica del Centro de Estudios en}

Administración Pública de la Facultad de Ciencias

Políticas y Sociales, Universidad Nacional

Autónoma de México

UNIVERSIDAD NACIONAL AUTÓNOMA DE MÉXICO

Rector: Dr. Enrique Luis Graue Wiechers

Secretario General: Dr. Leonardo Lomelí Vanegas

Secretario Administrativo: Ing. Leopoldo Silva Gutiérrez

Abogada General: Dra. Mónica González Contró

\section{FACULTAD DE CIENCIAS POLÍTICAS Y SOCIALES}

Directora: Dra. María Angélica Cuéllar Vázquez

Secretario General: Mtro. Arturo Chávez López

Secretario Administrativo: Mtro. José A. Santiago Jiménez

Jefe de la División de Estudios de Posgrado:

Dr. Roberto Peña Guerrero.

Jefa de la División de Educación Continua y Vinculación:

Mtra. Alma Iglesias González

Jefa de la División del Sistema Universidad Abierta y Educación a

Distancia: Lic. Yazmín Gómez Montiel

Jefe de la División de Estudios Profesionales:

Dr. Maximiliano García Guzmán

Coordinador del Centro de Estudios en Administración Pública:

Dr. Adán Arenas Becerril

Coordinador de Informática:

Ing. Alberto Axcaná de la Mora Pliego

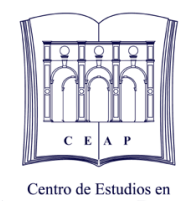

Administración Pública FCPyS UNAM

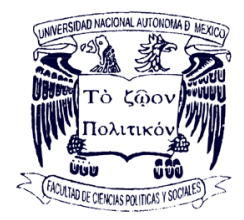

LA REVISTA

Director de la Revista:

Dr. Maximiliano García Guzmán

Secretario Técnico de la Revista:

Mtro. César C. Dionicio

Consejo Editorial:

Dr. Alejandro Navarro Arredondo

Dr. Arturo Hernández Magallón

Dr. Carlos Juan Núñez Rodríguez

Dra. Fiorella Mancini

$\operatorname{Dr}(\mathrm{c})$. Eduardo Villarreal

Dr. Roberto Moreno Espinosa

Diseño, integración y publicación electrónica: Coordinación de Informática, Centro de Investigación e Información Digital, FCPyS-UNAM. Coordinación de producción: Alberto A. De la Mora Pliego. Diseño e Integración Web: Rodolfo Gerardo Ortiz Morales. Programación y plataforma Web: Guillermo Rosales García.

ENCRUCIJADA REVISTA ELECTRÓNICA DEL CENTRO DE ESTUDIOS EN ADMINISTRACIÓN PÚBLICA, Año 10, No.31, enero-abril 2019 , es una publicación cuatrimestral editada por la Universidad Nacional Autónoma de México a través de la Facultad de Ciencias Políticas y Sociales y el Centro de Estudios en Administración Pública, Circuito Mario de la Cueva s/n, Ciudad Universitaria, Col. Copilco, Del. Coyoacán, C.P. 04510, México, D.F., Tel.(55) 56229470 Ext. 84410 , http://ciid.politicas.unam.mx/encrucijadaCEAP/, ceap@politicas.unam. mx. Editor responsable: Dr. Maximiliano García Guzmán. Reserva de Derechos al uso Exclusivo No. 04-2011-011413340100-203, ISSN: 2007-1949. Responsable de la última actualización de este número, Centro de Estudios en Administración Pública de la Facultad de Ciencias Políticas y Sociales, Mtro. César C. Dionicio, Circuito Mario de la Cueva s/n, Ciudad Universitaria, Col. Copilco, Del. Coyoacán, C.P. 04510, México D.F., fecha de la última modificación, 5 de enero de 2019.

Las opiniones expresadas por los autores no necesariamente reflejan la postura del editor de la publicación. Se autoriza la reproducción total o parcial de los textos aquí publicados siempre y cuando se cite la fuente completa y la dirección electrónica de la publicación 